\title{
Learning Sciences Theories, Principles, and Practices Comprising a Framework for Designing a New Approach to Health Professions Education
}

\author{
Frank J. Papa ${ }^{1}$ (D \\ Accepted: 15 October 2020 / Published online: 27 October 2020 \\ (C) International Association of Medical Science Educators 2020

\section{The Call for Curricular Reform in Health Professions Training Programs}

Over the past 20 years, external forces have placed substantial pressure on health professions training programs to adopt new, evidence-based approaches to instruction and assessment. Unfortunately, while learning sciences researchers have forwarded a number of theories, principles, and practices useful for launching evidence-based curricular reforms, the majority of health profession educators and administrators are not familiar with this continually evolving body of research. The purpose of this manuscript is to provide a brief introduction to the following: (1) the broad goals of the learning sciences, (2) a review of those theories providing insights into the cognitive factors enabling the development of the mind and competence, and (3) a framework consisting of those specific principles and practices which can inform educators and administrators seeking to design, develop, and implement evidencebased, learning sciences-driven approaches to training and assessing tomorrow's health care providers.

\section{An Introduction to the Learning Sciences}

The learning sciences consist of a multi-disciplinary, evidence-driven group of researchers dedicated to pursuing two primary goals [1]. First is to produce continually evolving "models of mind" (theories, principles, and practices) by which educators might construct a learning environment which effectively and efficiently develops the cognitive factors enabling the development of problem-solving

Frank J. Papa

frank.papa@unthsc.edu

1 University of North Texas Health Science Center, 3500 Camp Bowie Boulevard, Fort Worth, TX 76110, USA capabilities. Second is to produce continually evolving "models of competence" by which educators might construct reliable, valid, and meaningful assessments of the cognitive factors enabling the transformation of novices into competent problem solvers. Collectively, these models of the mind and competence can be used to formulate new, evidence-based approaches to education.

In the following, I first briefly review the contributions of a few cognitive sciences researchers/theorists (Bloom, Elstein, and Gagne) whose work has contributed to the medical curricular reform initiatives that dominated the latter half of the twentieth century (Problem-Based Learning and the Presentation Curriculum) [2]. Next, I briefly review the contributions of a few computational and neurocognitive researchers whose work has not yet found its way into health sciences education but is likely to be appreciated over the next 10-20 years as the basis for constructing artificial intelligence-driven computer-based tutors, high-fidelity simulators, and virtual and augmented reality-based approaches to instruction and assessment.

\section{Cognitive Sciences-Based Models of Mind and Competence}

Benjamin Bloom In the 1950s, Bloom developed an educational philosophy that would become the foundation of modern education [3]. Simply put, he conceptualized the mind as a hierarchically ordered, progressively evolving phenomenon, a perspective representing an extension of Piaget's earlier insights suggesting that the cognitive development of children proceeded in stages [4]. Bloom posited that educators would more effectively and efficiently develop the minds of their learners via the establishment of six broad categories of hierarchically ordered educational objectives: (1) acquiring and recalling information, (2) comprehending the potential utility 
of the acquired information for performing tasks such as problem solving, (3) applying recently acquired information during problem-solving activities, (4) analyzing/reflecting upon the cognitive factors (knowledge and skills) contributing to successful and unsuccessful problem-solving activities, (5) synthesizing/evaluating those cognitive factors contributing to a more effective and efficient approach to problem solving, and (6) creating/generating for oneself, and/or sharing with others, insights gained from previous efforts at analyzing/ reflecting upon and synthesizing/evaluating the knowledge and skills required to more effectively and efficiently solve previously encountered problems. Evidence demonstrating the utility of elements of Bloom's approach in medical education has been published [5].

Arthur Elstein In the late 1970s, Elstein sought to understand how the performance of expert clinicians differed from that of non-experts, a work representing an early contribution to the formation of a medical model of competence [6]. At the time, it was widely assumed that these expert/novice performance differences were due to the superiority of the experts' generalizable problem-solving processes (hypothetico-deductive reasoning). Elstein therefore sought to identify the specific differences in these two groups' problem-solving processes, use them to formulate a better approach to developing these generalizable problem-solving skills, and thereby improve the novices' performance of clinical tasks such as differential diagnosis. His research revealed that the performance of both experts and non-experts varied with the specific clinical problems encountered (i.e., patient case presentations and their diagnosis). Evidence that the subjects' diagnostic performance varied from one case to another, caused Elstein to conclude that diagnostic competence was problem-specific because it was knowledge-based (i.e., dependent upon whether the clinician had knowledge specifically relevant to solving/ diagnosing the specific case/problem at hand), rather than predicted upon generalizable problem-solving skills. This finding should have caused educators to rethink, if not abandon their belief in the primacy of generalizable problem-solving skills in clinical reasoning. Unfortunately, contemporary medical education largely remains grounded in this belief.

Robert Gagne In the 1970s, Gagne took a position somewhat orthogonal to that of Bloom [7], a position from which he posited that the progressive development of mind (e.g., Bloom's six stages of development) was predicated upon the development of five core cognitive capabilities. They were as follows: (1) information (formation of a knowledge base), (2) intellectual skills, (3) cognitive strategies and metacognitive skills, (4) sensory-motor skills, and (5) attitudes. Gagne's contributions complimented Bloom's work in two ways. First, Gagne created a hierarchically ordered listing of specific intellectual skills enabling learners to progressively transform whatever information they had acquired, into the deeper knowledge (i.e., procedural knowledge) needed to apply, analyze/reflect, synthesize/evaluate, and create/generate solutions for the problem at hand. Gagne described these specific intellectual skills in terms of their ability to formulate the following: (1) discriminations, (2) concrete concepts, (3) defined concepts, (4) rules, and (5) higher order rules. Second, Gagne also described cognitive strategies as the capacity to organize or sequence rules and higher order rules so that problem solving might be more efficient and effective, and metacognitive skills as the ability to self-monitor one's performance, and the ability to learn how to learn.

\section{The Application of Cognitive Sciences-Derived Models of Mind and Competence in Health Professions Education}

In the 1970s, Barrows introduced his Problem-Based Learning (PBL) curricular model, the first medical curricular reform initiative to incorporate elements of Bloom's notion of the progressive, developmental nature of the mind [8]. More specifically, PBL provided students a small-group, problemfocused, case-based learning environment; opportunities to both comprehend and apply (Bloom's stages 2 and 3) any information they had acquired (stage 1), and reflect upon (stage 4) any additional information needed to solve the several tasks and questions posed by the case at hand. PBL would thereby become widely perceived as a substantive improvement over both Discipline and Systems curricular models, curricula which had long assumed that the students' intellect was adequately developed via the passive acquisition of information via reading assignments and lectures presented in large classroom settings (i.e., activities largely directed towards stage 1 in Bloom's taxonomy; information acquisition and recall).

In the 1990s, Mandin and Harasym built their Presentation Curriculum upon Elstein's understanding of the problemspecific (e.g., acute chest pain, dyspnea, syncope), knowledge-based nature of competence [9]. The Presentation Curriculum was different from PBL in that it (1) organized its pre-clerkship curriculum around 126 primary care-oriented patient presentations, (2) identified a core set of common and/or important disease differentials for each presentation, (3) explicitly imparted faculty-derived cognitive strategies (diagnostic schemas) for students to use when performing the core problem-solving task of differential diagnosis, and (4) created presentation-focused, small groupbased application opportunities wherein students applied their schemas (Gagne's rules and higher order rules) as the basis for differentiating the various diseases most likely to cause the patient presentation/problem at hand. However, one largely 
unappreciated innovation introduced by the Presentation Curriculum is that its numerous presentation-specific application sessions represented the beginnings of a "modular," presentation/problem-specific approach to curricular design. In 2018, the AAMC reported that pre-clerkship curricular reform initiatives were underway by $77 \%$ of its member schools, and that Presentation-oriented curricular initiatives were the most commonly pursued [10].

In the early 2000s, Michaelsen advanced a codified approach to small-group, case-based learning, an approach termed Team-Based Learning (TBL) $[11,12]$. TBL begins with the acquisition of information (Bloom's stage 1), followed by individual and team-based assessments representing the learner's ability to recall the acquired information and demonstrate their comprehension of its potential utility (stage 2). This is followed by case-based application opportunities (stage 3) wherein both the individual and collective contributions of each team member lead to the construction of a shared understanding of the knowledge needed (stage 4, and possibly stages 5 and 6) to perform the tasks associated with the problem at hand. It should be noted that TBL also incorporates elements of the work of constructivist theorists such as Ausubel, Piaget, and Vygotsky [13]. Researchers suggest that learning is expedited by working in small groups where students have an opportunity to both develop and share a negotiated, cooperative/collaborative understanding of both what they already know, and the new knowledge needed, to comprehend (Bloom stage 2), apply (stage 3), and analyze/reflect upon (stage 4), in order to solve the problem at hand.

It should also be noted that the flipped classroom initiative which captivated many educators in the mid-2010s also had its roots in Bloom's notion of the hierarchically ordered, progressive development of mind. That is, in order to optimize the time available to progressively develop the mind, learners should first acquire information prior to class (complete a preclassroom homework assignment), so that in-class time could be utilized to support the development of comprehension, engage in application opportunities, and potentially support the development of higher level intellectual capabilities such as analysis, synthesis, and generation.

\section{Computational and Neurocognitive Sciences-Based Models and Simulations of Mind and Competence}

In the 1960s, Newell and Simon created a new learning sciences research paradigm via the conceptualization of human cognition (reasoning and/or problem solving) in terms of computationally based, computer-driven information processing algorithms [14]. Their paradigm would enable generations of researchers to both "model and simulate" how various forms of acquired information/knowledge, and information processing mechanisms (i.e., theorized cognitive processes such as intellectual skills, cognitive strategies, and metacognition), might perform problem-solving tasks.

They suggested that cognitive processes (i.e., information processing mechanisms) were broadly applicable or generalizable across any number of problems while information/ knowledge was of limited scope (i.e., only useful for specific problems and tasks). These generalizable processes were referred to as "weak heuristics" in that without task/problemspecific information/knowledge, they were unable to effectively reason/problem solve. They referred to the narrow, problem/task-specific information/knowledge as "strong heuristics" in that it was essential to solve a specific problem/task.

In the 1980s, Anderson would utilize algorithms and computers to further explore the nature of these strong knowledgebased heuristics [15-17]. He created algorithms that would model two distinct forms of these knowledge-based constructs and referred to them as declarative and procedural knowledge. Declarative knowledge represented fact-based constructs (i.e., knowledge of "this/that"; the type of information/knowledge imparted by books, lectures, faculty, etc.). Procedural knowledge represented a deeper type of knowledge stored in memory in the form of "if-then" propositions or production rules. He posited that procedural knowledge represented "how to" perform specific tasks associated with specific problems.

In the 1980s and 1990s, Ericsson (a cognitive sciencesbased researcher) observed that the capacity to successfully develop and apply knowledge and cognitive processes could be enhanced if the leaner's application opportunities were first focused on performing the task(s) associated with the problem at hand, and immediately followed by task/problem-specific feedback ("focused practice and deliberate feedback") [18]. In essence, Ericsson posited that the use of multiple presentationspecific and task-focused application opportunities, in-time performance assessment, and immediate expert guidance/ feedback, leads to the refinement of procedural knowledge and information processing mechanisms enabling their transfer to analogous problems and tasks, a means of enabling the effective and efficient transformation of novices into competent individuals [19-22]. Evidence of the potential utility of Ericsson's framework in medical education follows.

Despite intensive training, medical students have difficulty reliably diagnosing case vignettes analogous to those previously solved [23]. The inability to solve a new case presentation analogous to, and perhaps slightly harder than case presentations previously solved, is referred to as the "content" or "case specificity" phenomenon; the learning sciences refer to it as the "transfer problem." [24] The need to effectively address transfer-related impediments to improved diagnostic performance is likely to become increasingly appreciated given evidence of an estimated $10 \%$ diagnostic error rate among contemporary practitioners [25-27]. Medical education researchers have demonstrated that human-mediated 
instructional activities based upon this methodology lead to improvements in diagnostic reasoning [28].

However, a new generation of computer-based tools would be needed to both model and simulate how neural tissuebased memory traces (knowledge structures) and neurophysiologically mediated information processing mechanisms (Gagne's intellectual skills, cognitive strategies, and metacognitive skills) solved problems. At their most basic level, such tools (called artificial neural networks or ANNs) model how a neural unit, provided multiple exposures to a given stimulus (practice opportunities; preferably problem and task-specific as suggested by Elstein), followed by feedback signaling whether the neural unit's response to each stimulus was correct or incorrect (Ericson's notion of focused practice and deliberate feedback), produces incremental adjustments in the weightings which the unit will use to respond to its next exposure to a similar stimulus (Anderson's procedural knowledge).

Over time, an iterative cycle of stimuli (in the form of practice opportunities), feedback, and neural weighting adjustments (i.e., increases/decreases in the strength of neuro-associative links) gradually increase the ANN's capacity to correctly respond to future exposures of similar stimuli [29], an affirmation of Ericsson's observations. Cognitive neurosciences researchers are also using neuro-imaging techniques to lend credence to the hypothesized existence of different knowledge structures by demonstrating that declarative knowledge appears to be stored in the hippocampus and medial temporal lobe while propositional or procedural knowledge resides in cortical and subcortical anatomical structures [30].

Collectively, these computational and neurocognitive paradigms, computer-based algorithms (ANNs), and research methods can be used to model theories posited by both the previously mentioned cognitive researchers and a new generation of neural network-based theories (memory-based knowledge structures in the form of procedural knowledge) and neurocognitive processes (i.e., models describing how neural weights are strengthened/weakened in terms of their "associative links"). The importance of these paradigms, algorithms, and methods will become increasingly clear over the next 10-20 years as practitioners begin to appreciate their utility for solving complex medical problems (i.e., via diagnostic decision support tools) and in the development of individualized therapies/protocols for treating complex disorders involving malignancies and genetics.

However, whether faculty will be provided the training and time needed to learn how to use these approaches in their interactions with learners (at these highly granular levels of knowledge-based constructs and cognitive processes) remains to be seen. In the meantime, work has been undertaken to transform these new paradigms, tools, and methods into the theories, principles, and practices [31-41] needed to formulate a framework useful for driving the instructional activities of the artificial intelligence-driven tutors/avatars that will reside within tomorrow's high-fidelity simulators, and virtual and augmented reality-based learning environments.

\section{The Evolving Influence of Learning Sciences-Based Theories upon ACGME- and AAMC-Driven Curricular Initiatives}

In 1999, ACGME launched its competencies initiative, a movement identifying six clinical performance domains which residency programs are expected to teach to and assess (i.e., patient care, biomedical knowledge, professionalism, communication, systems, and practice-based competencies) [42]. Residency programs were in turn required to define their own specialty-specific, domain, and subdomain competencies. For example, specific tasks such as gathering and synthesizing essential and accurate information to define each patient's clinical problems, and developing and achieving a comprehensive management plan for each patient, represent two Internal Medicine subcompetencies (tasks) with the domain of patient care [43]. While not widely appreciated, the ACGME's and specialty colleges' competencies initiatives represent an "outcomes-oriented" and task-driven approach to medical training.

However, residency programs also needed guidance regarding how to develop a codified, specialty-specific set of competence-oriented performance rubrics; tools that would guide faculty in their assessments of a resident's evolving competencies. The initial development of these rubrics was largely predicated upon the work of the Dreyfus brothers, who in 1980 introduced (in a manner similar to Bloom) the concept of a progressive, developmentally based model of both the mind and competence, a model suggesting that the mind and competence progressed through five stages defined as novice, competence, proficiency, expertise, and mastery [44]. Each specialty college would use the notion of progressively developed levels of mind/competence to construct a milestone-based, rubric-driven approach to the establishment of performance criteria (i.e., level of progress); an explicit definition of the level of performance to be demonstrated by each resident for each competency associated with the various tasks represented in each domain and subdomain. These milestones represent a rudimentary acknowledgment of not only Elstein's notion of the problem-specific nature of competence, but also the task-specific nature of competence (Newell, Simon, and Anderson); an acknowledgment that would be the basis for the following AAMC initiative [45].

In 2014, the AAMC established 13 entrustable professional activities (EPAs) as undergraduate proficiencies to be attained prior to entering residency programs (e.g., specific tasks such as gathering a history and performing a physical examination, prioritizing a differential diagnosis following a clinical encounter) [46]. These 13 EPAs (or task-specific competencies) 
represented an intermediate level of granularity somewhere between broad, specialty-defined subcompetencies/milestones, and the more narrowly defined problem-specific competencies identified by Elstein. In summary, the curricular reforms initiated by the ACGME, specialty colleges, and AAMC over the past 20 years represent the gradual endorsement and implementation of several learning sciences-derived models of the mind and competence.

Curiously, in 2020, the NBME reported their intention to replace its numerically based assessment of competence with a single pass/fail grade [47]. The primary driver for this change was sensitivity to the psycho-social impact of a high-stakes examination on medical students; a change which mirrors the increasing adoption of pass/fail-based assessments by many medical schools. Traditionally, medical schools have used normreferenced metrics rather than competence- or mastery-based metrics as the basis for reporting and rank ordering a learner's performance in relationship to each basic and clinical sciences discipline course offered by their curriculum. Unfortunately, the lumping of performance across many problems and tasks (as is increasingly done in medical schools, and as is now the intention of the NBME), into a single pass/fail decision, would appear to be at odds with what the learning sciences has forwarded, and the ACGME, specialty colleges, and AAMC have been working towards. That is, an embrace of the problem-specific, task-specific, and knowledge-based nature of competence.

\section{Moving Forward}

The author suggests that faculty and administrators at undergraduate health professions programs (MD, DO, PA, NP, and RN) study and seriously reflect upon learning sciences-based research into the problem-specific, task-specific, and knowledge-based nature of competence. Further, they explore and define increasingly granular, ACGME-derived subdomains (tasks) in preparation for a shift towards a competency- and outcomesoriented approach to undergraduate health professions education [ 48]. For example, when training to patient care competencies in the undergraduate curriculum (i.e., in clinically oriented pre-clerkship- and clerkship-based coursework), core health care provider tasks would include diagnosis, treatment, and management, while the primary task in the domain of biomedical knowledge would appear to be explanation. After the establishment of a problem- and task-specific approach to undergraduate training, administrators and educators can then undertake the arduous work of developing mastery-based assessment rubrics designed to reliably, validly, and meaningfully assess problem- and task-specific competencies at the undergraduate level.

\section{Learning Sciences Principles and Practices Serving as a Framework for Designing a New Approach to Health Professions Education}

Following is a framework consisting of those learning sciences principles and practices which can be used to drive the development of a codified, evidence-based approach to MD, DO, PA, NP, and $\mathrm{RN}$ training programs. This framework would represent, in part, an extension of Calgary's Presentation Curriculum. A new curricular initiative which the author calls a Presentation-specific, Task-focused, Application-oriented Curriculum (PTAC). A curriculum designed to support the development of a more effective and efficient learning environment; a curriculum seeking evidence-based approaches to improving patient care outcomes.

Principle \#1: Train to problem/presentation-specific and task-specific competencies.

Practice \#1: Identify the specific clinical problems/ presentations and tasks associated with each broadly defined domain of competence relevant to each health professions training program.

Practice \#2: Organize both clinical and basic sciences curricular content into domain-specific and problem/ presentation-specific instructional modules.

Practice \#3: Within each module, design instructional activities which both impart problem/presentation- and task-specific information (declarative knowledge), and more importantly, support learners in its transformation into the procedural knowledge needed to perform the clinical tasks associated with the specific problem/ presentation at hand.

Practice \#4: Expedite the transformation of declarative knowledge into procedural knowledge by exposing learners to multiple application opportunities for each problem and task.

Practice \#5: Optimize the development of procedural knowledge by providing learners with an immediate, formative assessment of their performance followed by guidance/feedback regarding their specific strengths and deficiencies.

Practice \#6: Focus feedback upon the specific knowledge-based constructs (both declarative and procedural) and cognitive processes (information processing mechanisms), theorized as enabling the performance of the task at hand.

Principle \#2: Summative assessment should be aligned with instruction such that both represent the same level of specificity or granularity.

Practice \#1: Create summative assessment procedures which both test and report performance at the same level 
of specificity/granularity as that trained to in the curriculum (i.e., assess and report performance in terms of problem/presentation-specific and task-specific metrics). Practice \#2: Develop and utilize explicit mastery-based criteria to determine whether a student's summative performance in a given problem or task merits a pass or fail (i.e., replace norm-referenced methods and global pass/ fail metrics with mastery-based methods and problem/ presentation- and task-specific performance metrics).

Practice \#3: Procure the resources and allow for the time needed to create the number of problem/presentation- and task-specific test items necessary to produce a reliable summative assessment of the students' problem- and task-specific competencies.

Principle \#3: Administrative responsibilities for the design and execution of undergraduate and graduate health professions curricula should be in hands of individuals dual trained in both their respective clinical or basic science discipline and the learning sciences.

Practice \#1: Undergraduate and graduate health professions training programs should designate time and resources sufficient to hire and/or train a core group of basic and clinical science faculty to direct their training programs.

\section{Summary}

The purpose of this manuscript was to provide a brief introduction to the following: (1) the broad goals of the learning sciences, (2) a review of those theories providing insights into the cognitive factors enabling the development of the mind and competence, and (3) a framework consisting of those specific principles and practices which can inform educators and administrators seeking to design, develop, and implement learning sciences-driven approaches to health professions training programs. The adoption of instructional and assessment frameworks based upon these and other learning sciences theories, principles, and practices represents a paradigm shift for health professions programs. Health care program administrators and faculty are encouraged to explore for themselves the learning sciences literature so that they might better understand, apply, and evaluate the utility of the models of mind and competence continually emerging from this somewhat complex, yet increasingly important educational research.

Author's Contribution Entirely that of the sole, submitting author

Data Availability Not applicable

\section{Compliance with Ethical Standards}

Conflict of Interest The author acknowledges ownership of a company called Advanced Curricular Designs and Education Technologies (ACDET), a company which produces and sells a high-fidelity abdominal simulator.

Ethics Approval Not applicable

Consent to Participate Not applicable

Code Availability Not applicable

\section{References}

1. Sawyer RK. Introduction: the new science of learning. In: Sawyer RK, editor. The Cambridge handbook of the learning sciences. New York: Cambridge University Press; 2006. p. 1-16.

2. Papa FJ, Harasym PH. Medical curriculum reform in North America, 1765 to the present: a cognitive science perspective. Acad Med. 1999;74(2):154-64.

3. Bloom BS, editor. Taxonomy of educational objectives: the classification of educational goals. Handbook I: Cognitive domain. New York: David McKay Company, Inc; 1956.

4. Piaget J. Origins of intelligence in the child. London: Routledge \& Kegan Paul; 1936.

5. Papa FJ, Schumacker RE. Hierarchically ordered instructional activities and the development of clinically relevant competencies: a sequential path model. Multiple Linear Regression Viewpoints. 2009;35(1):30-5.

6. Elstein AS, Shulman LS, Sprafka SA. Medical problem solving: an analysis of clinical reasoning. Cambridge: Harvard University Press; 1978.

7. Gagne RM, Wager WW, Golas KC, Keller JM. Principles of instructional design. Belmont, Thomson-Wadsworth. 2005.

8. Barrows HS, Tamblyn RM. Problem-based learning: an approach to medical education. New York: Springer Publishing; 1980.

9. Mandin H, Harasym P, Eagle C, Watanabe M. Developing a clinical presentation curriculum at the University of Calgary. Acad Med. 1995;70:186-93.

10. Mavis B. Curriculum change: reflections on what and how we teach. https://www.aamc.org/system/files/2019-10/mededcurriculum-inventory-context-september-2019.pdf (Accessed Mar 29, 2020).

11. Michaelsen LK, Knight AB, Fink LD, editors. Team-based learning: a transformative use of small groups. New York: Praeger; 2002.

12. Seidel CL, Richards BF. Application of team learning in a medical physiology course. Acad Med. 2001;76(5):533-4.

13. Cakir M. Constructivist approaches to learning in sciences and their implications for science pedagogy; a literature review. Int J Environ Sci Educ. 2008;3(4):193-206.

14. Newell A, Simon HA. Human problem solving. Englewood Cliffs: Prentice-Hall; 1972.

15. Anderson JR. ACT: a simple theory of complex cognition. Am Psychol. 1996;51(4):355-65.

16. Anderson JR. Cognitive skills and their acquisition. Hillsdale: Lawrence Erlbaum; 1981.

17. Anderson JR. Cognitive psychology and its implications. 3rd ed. New York: W.H. Freeman; 1990.

18. Ericsson KA. The search for general abilities and basic capacities: theoretical implications from the modifiability and complexity of 
mechanisms mediating expert performance. In: Sternberg RJ, Grigorenko EL, editors. Perspectives on the psychology of abilities, competencies, and expertise. New York: Cambridge University Press; 2006. p. 93-125.

19. Ericsson KA, Krampe RT, Tesch-Romer C. The role of deliberate practice in the acquisition of expert performance. Psychol Rev. 1993;100:363-406.

20. Ericsson KA. Deliberate practice opportunities and the acquisition and maintenance of expert performance in medicine and related domains. Acad Med. 2004;79(10 Suppl):S70-81.

21. Bransford JD, Brown AL, Cocking RR. How people learn: brain, mind, experience, and school. Committee on Developments in the Science of Learning. Commission on Behavioral and Social Sciences and Education, National Research Council. Washington, DC: National Academy Press; 2000.

22. Kirschner PA, Sweller J, Clark RE. Why minimal guidance during instruction does not work: an analysis of the failure of constructivist, discovery, problem-based, experiential, and inquiry-based teaching. Educ Psychol. 2006;41(2):75-86.

23. Perkins DN, Salomon G. Are cognitive skills context bound? Educ Res. 1989;18(1):16-25.

24. Kimball DR, Holyoak KJ. Transfer and expertise. In: Tulving E, Craik FI, editors. The Oxford handbook of memory. New York: Oxford University Press; 2000. p. 109-22.

25. Garber ML, Berner ES. Diagnostic error: is overconfidence the problem? Am J Med. 2008;121(5A):S2-S23.

26. Berner ES. Diagnostic error in medicine: introduction. Adv Health Sci Educ Theory Pract. 2009;14(suppl 1):1-5.

27. Balogh EP, Miller BT, Ball JR, editors. Improving diagnosis in health care. Committee on diagnostic error in health care, Institute of Medicine. Washington, DC: National Academies Press; 2015.

28. Hatala RM, Norman GR, Brooks LR. Practice makes perfect: the critical role of mixed practice in the acquisition of ECG interpretation skills. Adv Health Sci Educ Theory Pract. 2003;8(1):17-26.

29. Churchland PS. Neurophilosophy: towards a unified science of mind/brain. Cambridge: MIT Press; 1992.

30. Poldrack RA, Foerde K. Category learning and the memory systems debate. Neurobio Rev. 2008:197-205.

31. Papa FJ, Meyer S. An expert program shell designed for extracting "disease prototypes" and their use as models for exploring the "strong problem solving methods" employed in clinical reasoning. In: Hart IR, editor. Further developments in assessing clinical competence. Quebec: Heal Publications; 1987. p. 354-64.

32. Papa FJ, Shores JH, Meyer S. The Use of a pattern recognitionbased, prototype-driven research tool to study the cognitive constructs in medical decision making. In: Hart IR, Harden RM, Des Marchais J, editors. Current developments in assessing clinical competence. Ottawa: Can-Heal Publications; 1992. p. 210-3.

33. Papa FJ, Stone R, Aldrich D. A neural network-based differential diagnosis assessment procedure. J Educ Comput Res. 1994;10(3): 269-82.

34. Papa FJ, Stone RC, Schumacher RE. Artificial intelligence-based differential diagnosis assessment procedures: theoretical advantages. In: Harden RM, Hart IR, Mulholland H, editors.
Approaches to the assessment of clinical competence (Part 2). Page Brothers: Norwich; 1992. p. 447-51.

35. Papa FJ, Stone RC \& Aldrich DG. Artificial intelligence-driven knowledge base analysis: individualized and intelligent tutorials. Proceedings of the Eleventh International Conference on Technology in Education. London, March 1994.

36. Stone RC, Papa FJ \& Aldrich DG. The logistical advantages of a neural network-based categorization skills assessment instrument. Proceedings of the eleventh International Conference on Technology in Education. London, March 1994.

37. Papa FJ. A dual processing theory based approach to instruction and assessment of diagnostic competencies. Medical Science Educator, October 2016. Springer.

38. Papa FJ, Li F. Evidence of the preferential use of disease prototypes over case exemplars among year one medical students prior to and following diagnostic training. Diagnosis. 2015;2(4):217-25.

39. Papa FJ, Kalinowski K. Human and artificial intelligence in differential diagnosis. Medical Informatics, Melchor Sanchez, Editor, January 2014, Elsevier.

40. Papa FJ. Learning sciences principles that inform new approaches to diagnostic training for future health care providers. Diagnosis. 2014;1(1):125-9.

41. Papa FJ, Oglesby MW, Aldrich DG, Schaller F, Cipher DJ. Improving diagnostic capabilities of medical students via application of cognitive sciences-derived learning principles. Med Educ. 2007;41(4):419-25.

42. Holmboe ES, Edgar L, Hamstra S. The Milestones Guidebook. https://www.acgme.org/Portals/0/MilestonesGuidebook.pdf. (Last accessed on Mar 29, 2020)

43. The Internal Medicine Milestone Project. https://www.acgme.org/ Portals/0/PDFs/Milestones/InternalMedicineMilestones.pdf. Last accessed Apr 2020

44. Dreyfus Stuart E, Dreyfus Hubert L. A five-stage model of the mental activities involved in directed skill acquisition. Washington, DC: Storming Media. 1980.

45. Merrill MD. A task-centered instructional strategy. J Res Technol Educ. 2007;40(1):33-50.

46. Lomis K, Amiel JM, Ryan MS, Esposito K, Green M, StagnaroGreen A, et al. Implementing an entrustable professional activities framework in undergraduate medical education: early lessons from the AAMC Core Entrustable Professional Activities for Entering Residency Pilot. Acad Med. 2017;92(6):765-70.

47. George J. No more numerical scores for USMLE Step 1 Exam. https://www.medpagetoday.com/hospitalbasedmedicine/ graduatemedicaleducation/84914 (accessed Mar 29 2020)

48. Olson A, Rencic J, Cosby K, Rusz D, Papa F, Croskerry P, et al. Competencies for improving diagnosis: an interprofessional framework for education and training in health care. Diagnosis. 2019;6(4):335-4.

Publisher's Note Springer Nature remains neutral with regard to jurisdictional claims in published maps and institutional affiliations. 